\title{
Review of Claudia Nelson's "Sex and the Single Boy: Ideals of Manliness and Sexuality in Victorian Literature for Boys" (1989)
}

Baker M. Bani-khair ${ }^{*}$, Abdullah Badarneh ${ }^{2}$, Majed Al-Qura'n², Fatimah Sarahneh²

${ }^{1}$ Department of English, Hashemite University, Zarqa, Jordan

${ }^{2}$ Hashemite University, Jordan

Corresponding Author: Baker M. Bani-khair, E-mail: bakribakr@yahoo.com

\section{ARTICLE INFO}

Article history

Received: September 10, 2018

Accepted: November 19, 2018

Published: February 28, 2019

Volume: 10 Issue: 1

Advance access: January 2019

Conflicts of interest: None

Funding: None

Key words:

Children's Literature,

Manliness,

Masculinity,

Victorian Ideals,

Ethics,

Claudia Nelson

\begin{abstract}
This article traces the idea of manliness, masculinity and sexuality, and its connection with children's literature in the Victorian age. As such, it sheds light on the stereotypes that accompanied the prevalent conceptions about masculinity and manliness in the Victorian age. Additionally, it explains how sexuality was considered to be an issue that had strict ideals, stereotypes, rules, and restrictions because it was governed by the social, religious and structural pedagogy of the society. According to the Victorian ideals, "manliness" was regarded as a moral and religious virtue that can control sexual desires, and lessen the level of danger and threat to the moral structure of the society. Within the framework of manliness and masculinity, the article stresses the point that children's literature was certainly the pivotal focus that reflects these stereotypes or the Victorian ideals since it was part of the educational, ethical, religious and social life, especially for children's education and upbringing.
\end{abstract}

\section{INTRODUCTION}

This article traces the idea of manliness, masculinity and sexuality, and its connection with children's literature in the Victorian age. As such, it sheds light on the stereotypes that accompanied the prevalent conceptions about masculinity and manliness in the Victorian age. Additionally, it explains how sexuality was considered to be an issue that had strict ideals, stereotypes, rules, and restrictions because it was governed by the social, religious and structural pedagogy of the society. According to the Victorian ideals, "manliness" was regarded as a moral and religious virtue that can control sexual desires, and lessen the level of danger and threat to the moral structure of the society. Within the framework of manliness and masculinity, the article stresses the point that children's literature was certainly the pivotal focus that reflects these stereotypes or the Victorian ideals since it was part of the educational, ethical, religious and social life, especially for children's education and upbringing. However, it is important to note that such representations of Victorian ideals become different in the modern ages. Bani-Khair and Khawaldeh in "Then and Now: Approaches to Understanding
Children's Literature in Two Volumes," stress the idea that children's literature has begun to develop in the modern era leaving behind traditional Victorian conventions. They state that, "from the scholars' point of views, children's literature has developed and modified the criteria, rules and stereotypical literary patterns of the Victorian age. New standards have to replace the old ones with more profound ideas and representations that address the contemporary worries and concerns of the age." (81)

Nelson's article is complicated in terms of intertextuality and style. Part of the complexity the article creates for the reader is its references to many articles, books, and theories which one need to read in order to fully understand Nelson's argument. Nelson's article is structurally and thematically rich, therefore, it is difficult to read and analyze it in isolation from history, social theory, children's literature and the modern psychoanalytic criticism. The article's writing style matches the literary criticism it provides as Nelson seems to use careful diction and definitions. She seems frequently to define 'manliness' many times throughout the paper. It is noticeable that Nelson uses powerful language and phraseology 
from a Victorian and modern perspective as well, as we see in this quotation:

For ultimately it is impossible fully to gauge Victorian ideals of manliness without discussing also Victorian definitions of maleness, as sex moved inexorably out of the domain of the clergy and into that of the scientist. And the principal difference between the definitions of manliness before and after the shift in emphasis from self-control to happily normal boyhood mirrors a similar shift in sexual mores, as chastity often seemed undesirable and "Normalcy" edged out godliness. (526)

This example, and as many other examples, from her article shows us the depth of Nelson's understanding and analysis of 'manliness' in the Victorian age, as well as her careful approach to understand the implications of 'manliness 'as a moral, sexual, and social aspect of the Victorian age. Such an example adds much complexity to the reader; however, it guides the reader to think about other important possibilities associated with the definition of 'manliness'. She illustrates the dual relationship between 'manliness' and 'masculinity' in accordance with her view about the Victorian ideals from her own understanding of religion and science. As we see in the previous quotation, there are many terms that one needs to understand in relation to the Victorian history and ideals because each one of them gives a complete notion not just about 'manliness' but also about the Victorian age in general.

In fact, another important part of Nelson's approach in understanding and analyzing the Victorian ideals about 'manliness', and 'masculinity' relies heavily on her historical explanation of the development of children's literature during the $18^{\text {th }}$ century by focusing on the shifts and transformations that children's literature underwent during that era. Nelson traces these developments through giving powerful examples on this phenomenon from children's texts that were written during that extended period of time.

In fact, manliness as a Victorian virtue was a broad concept in the Victorian era as it represents several aspects. John Tosh in "Gentlemanly Politeness and Manly Simplicity in Victorian England" explained that manliness was very loose term in the Victorian era as it was linked to a number of ideals and conventions of the social life in general. He stated:

Manliness is an even more slippery concept. In nineteenth-century England the word was used in an extraordinary variety of contexts and it was repeatedly pushed in fresh directions by religious writers and social theorists, often in mutually inconsistent ways. In the name of manliness Victorian men were urged to work, to pray, to stand up for their rights, to turn the other cheek, to sow wild oats, to be chaste and so on. It is clear that the idea of manliness exercised a powerful hold over the Victorians, but the nature of that hold has been obscured by recent scholarship. (459)

Obviously, and in light of Victorianism and the ideals that spread and prevailed during that age, Nelson asserts and explained such ambiguity when she clarifies how 'manliness' was part of religion and spiritualism, and that its representation in children's literature meant to depict these stereotypes and to criticize them as well. Tosh also adds that manliness was an inseparable part of the popular culture which means that it interwined with the whole social system of Victorian life, he said that, "But manliness was more than a subject of learned disputation, more even than an educational tool; it was a guide to life, deeply rooted in popular culture, and often resistant to the redefinitions proposed by didactic writers." (459) Across different time periods, these gender stereotypes were viewed and analyzed by many Victorian writers, changing the prevalent perspectives about "masculinity".

\section{APPROACH AND STYLE}

Throughout the whole article, the writer's approach proves to depend heavily on the examples she gives to support her argument highlighting the patterns associated with sexuality and masculinity in the Victorian age. In addition to her historical approach in reading sexuality and masculinity in the Victorian age, she also approaches that theme from her analytical view which certainly makes it an interesting and successful discussion. She successfully supports her points of view with a lot of powerful and variant examples from children's literature through mentioning and citing many Victorian writers, thinkers and critics, like Virginia Woolf, Michel Foucault, Sherwood Anderson, Rudyard Kipling, and many others.

The author's style, techniques and approach always remind the reader to return to the main thesis of the article. Despite the fact that she extensively goes far away from the thesis through her frequent references to many theories, writers, and literature books, she consistently brings the reader's attention back to the main thesis simply because the whole article revolves around this central theme. She tries to highlight her central point every time she delves deep through the texts she refers the readers to. Interestingly enough, the reader does not lose his/her track when paying attention to the connections and associations she clearly makes to the central thesis. Despite the level of complexity the reader might encounter in understanding of these connections, the article remains focused and approachable. In addition to its density and richness, the article gives the reader the chance to think and criticize every time we read a new paragraph.

\section{CRITICAL ANALYSIS}

Nelson's article is clearly a criticism of the gender stereotypes that limit the view about human nature and the possibilities people have restricted themselves with over a long period of time especially during the Victorian age, particularly gender stereotypes and misconceptions. The article helps us understand how thinkers and writers have also viewed and criticized these stereotypes about 'manliness' and 'sexuality' through children's literature. Furthermore, the article makes a clear distinction between 'manliness' and 'masculinity' in children's literature through the psychological and religious interpretation of motives, wishes, and dreams, virtues, ethics, and spiritualism in some children's literature books. In each of the novels Nelson deals with, she actually takes the main protagonist to highlight the theme of 'manliness'. These protagonists in the novels she analyzes 
become self-conscious of their own masculinity as well as sexuality. She also explains the way masculinity and sexuality turn to become "manliness" towards the end of each novel when the protagonists arrive at awakening or self-epiphany after encountering a major turning point. Usually, the protagonists are young boys who refuse to surrender to social and religious stereotypes and as a result of their disobedience, they encounter big problems in their life.

One of the strengths throughout the whole article is that the writer seems to have a broad knowledge and solid foundation in the scholarship that has preceded this article. Nelson has given a huge and broad introduction to Victorianism, and seems to provide us with a lot of factual as well as historical information in light of the theories she uses and the references she makes to manliness and the Victorian stereotypes about masculinity and sexuality in general. She also refers to some anthropologists like, Darwin, psychoanalysts and biologists in order to show us the relationship of these stereotypes with science and biology in the $18^{\text {th }}$ century. A thing that gives the author much credibility is that she seems familiar with many literary works and novels in Children's Literature, in addition, to many critical essays. Despite the fact that she focuses on four important literary works in her article like Thomas Hughes's Tom Brown's Schooldays, Sherwood's The Fairchild Family, Sinclair's Holiday House, and other two important novels, Henty's Bonnie Prince Charlie, and Rudyard Kipling's The Jungle Book, she actually doesn't restrict her article with these only examples to support her argument, but she also touches many other secondary literary works in passing.

Interestingly enough, Nelson combines different kinds of writing strategies. She sometimes seems analytical as well as critical in her understanding of manliness; however, Nelson provides her own impression relying on feminism as we see in the conclusion when she maintains the classical Victorian tone within a new feminist mould. Besides her analytical and argumentative writing strategies, Nelson uses descriptive writing strategies when she frequently describes the children's literature books she refers the readers to in her explanation of the definition of "manliness" in the Victorian age.

\section{CONCLUSION}

It is interesting how Nelson could successfully organize her ideas, critical thoughts, and strategies in showing us the definition of 'manliness' from different dimensions. She shows a deep understanding of the subject matter through her clever variations of stylistic, linguistic, and semantic use of language which perfectly match the content. Despite the complexity of thought and style, Nelson could clarify a lot of important ideas about manliness and sexuality in Victorian literature. Nelson's analytical approach and writing styles have certainly given me the insight to deal with complicated narratives in children's literature. However, I think that psychoanalytic criticism would be a fascinating approach to understand the implications of 'manliness' and 'sexuality' in children's literature from a psychological point of view in relation to history, religion, feminism and gender studies. I think it is also important to go back through history before the Victorian age to see how 'manliness' is similar and different in literature from the ideals of 'manliness' in the Victorian age. For example, I think it will be interesting to think of how 'manliness' is different or similar from 'chivalry' or 'nobility' in the middle ages. I think that it will be helpful to look at similar aspects when tracing the development of 'manliness' through different ages to see how gender roles have been represented in literature.

Finally, the article has many strength points which make it a successful one. The author has successfully explained her argument using extensive references that all support her argument. Additionally, the author's logical argument, approach, writing style, stylistics, as well as syntax have all made this article a big success.

\section{REFERENCES}

Bani-Khair, Baker, Khawaldeh, Imad. "Then and Now: Approaches to Understanding Children's Literature in Two Volumes" Advances in Language and Literary Studies, 7(3), 80-84. 2016

Chandler, K. R. (2007). Thoroughly Post-Victorian, Pre-Modern Beatrix. "Children's Literature Association Quarterly, 32(4), 287-307: 41-44.

Nelson, Claudia. "Sex and the Single Boy: Ideals of Manliness and Sexuality in Victorian Literature for Boys." Victorian Studies 32.4 (1889): 525-50. Academic Search Complete. Web. 8 March. 2018.

Nelson, Claudia."Interdisciplinarity and Evolution: Victorian Studies as Ancestor," Victorian Review 33.1(Spring 2007): 41-44. Web 7 May. 2018.

Tosh. John. "Gentlemanly Politeness and Manly Simplicity in Victroian England" Transactions of the Royal Historical Society 12:455-72. Web 15 May 2018. 